\title{
Artes dos espaços - considerações sobre os nexos emocionais e identitários que os jovens criam com a realidade arquitetónica da escola
}

\author{
Liliana Couto \\ Faculdade de Belas Artes da Universidade do Porto e i2ADS
}

\section{Resumo}

O presente estudo analisa as narrativas que uma jovem construiu sobre os espaços escolares e que traduziu em duas imagens e um conjunto de expressões orais e escritas. Este testemunho, de ordem emocional, presta-se a ser analisado numa nova perspetiva neuro social que nos explicam como estas experiências não são acidentais, mas autobiográficas, integrando a história pessoal e a construção da nossa identidade.

Palavras-chave: espaços escolares; identidade; emoções; sentimentos; narrativa.

\section{Abstract}

This study analyzes the stories that a young girl built about school spaces and that herself presents in two images and in several written and oral statements. These stories, with emotional nature, lead us to do an analysis from a new neuro social perspective to explain how these experiences are not accidental, but autobiographical, integrating personal history and the construction of our identity.

Keywords: school spaces; identity; emotions; feelings; narrative.

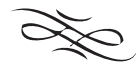

\section{Introdução}

Este artigo enquadra-se na tese sobre o sentido e o valor imaterial que os espaços escolares representam para os estudantes e fundamenta-se nos resultados da análise 
sobre o enunciado discursivo de um grupo de jovens que participou num trabalho de investigação sobre essa dimensão imaterial. Metodologicamente procedeu-se à análise desses discursos numa perspetiva narrativista, procurando saber como tais enunciados, elaborados a partir de experiências sensitivas dos espaços, são assimilados, ganham sentido pessoal e passam a integrar o processo autobiográfico e identitário dos jovens. Assim, recortamos desse conjunto, e exploramos neste texto, o trabalho de uma jovem naquele contexto de investigação.

Trata-se de um testemunho expresso em duas imagens e num conjunto de cinco depoimentos escritos em torno daquelas imagens e de experiências do passado nos espaços escolares, considerando-se, tal como defendido por Coulon (1995), que a questão de que a escola vivida no presente torna-se mais afetiva à medida que a sua recordação se dilui ou pode diluir-se no passado. De um ponto de vista metodológico, a análise de conteúdo mostra-se como o instrumento mais aplicável a esta fase do estudo. No entanto, no presente trabalho quisemos ir para além da sua utilização mais ortodoxa tentando explorar não apenas o significado que objetivamente o trabalho da jovem parece traduzir, mas encontrar também o seu significado oculto.

A análise organiza-se, então, em torno de 3 eixos principais.

No primeiro tentamos encontrar o sentido explícito do trabalho. Em seguida ousamos ver para além do que está obviamente escrito e fotograficamente testemunhado. Kerbrat-Orecchioni $(1980 ; 1986)$ abre-nos uma fímbria por onde penetrámos ao concluir: «dizer ou não dizer: esta é em parte para o locutor, a questão. Mas só em parte. Porque se pode simultaneamente dizer E não dizer». Assim sendo, quando relemos por diversas vezes o trabalho da jovem, fomos constatando que havia a explorar mais do que o seu significado mais evidente, o que nos levou a procurar e descobrir outras interpretações que agora estaríamos autorizados a utilizar "pela via do implícito" (KERBRAT-ORECCHIONI, 1986) e que orientamos para a análise da sua dimensão emocional no desejo de fazer a interpretação do que íamos encontrando numa dimensão mais socio emocional. Socorremo-nos, então, das neurociências para tentar descortinar o último eixo entre o que se vive emocionalmente e o que, por via dessas experiências, fica vinculadamente inscrito dentro de nós e, portanto, ficará a pertencer ao domínio da nossa identidade.

\section{Artes - emoções e interpretações}

Para nós, que acompanhamos todo o trajeto de pesquisa e descoberta dos jovens do grupo, sempre nos pareceu que o processo analítico por via da "análise de conteúdo" descrito minuciosamente por Bardin (2009) não era suficiente para descodificar o que os jovens iam dizendo. Apesar de nos socorrermos de vídeos ou gravadores para registrar o que posteriormente seria reduzido à escrita, esta, objetivamente, não conseguia tradu- 
zir o que muitas vezes emocionalmente se vivia e dizia na sala de trabalho. Passados a escrito, os enunciados, que na realidade transcrevem o que foi afirmado, deixavam-nos a sensação de que muitos episódios ficaram insuficientemente narrados e que a prosa parecia distanciar-se frequentemente da realidade vivida, ficando muito aquém de "serem o retrato fiel" de todas as vivências e sobretudo do clima entusiasmado que normalmente rodeava as sessões de trabalho. Da transcrição textual resultava sempre "um certo vazio", a desilusão muito frequente de que muitos dos enunciados nos pareciam como "déjà écrit" ou "déjà lu", isto é, transmitiam-nos a sensação de que os jovens repetiam sistematicamente as mesmas fórmulas. Seria quanto a nós importante encontrar outras leituras, novas abordagens, sem contudo nos deixarmos enredar em considerações opinativas ou subjetivas.

$\mathrm{Na}$ verdade, no caso vertente, se numa primeira leitura tudo se resume a meia dúzia de enunciados e duas imagens que, versando sobre o mesmo tema, não parecem ir muito além de banalidades e de ideias expressas pela aluna, não nos coibimos de partir à descoberta de pormenores (indicadores) que mostrassem que, no labor narrativo, a jovem diz muito provavelmente muito mais do que nos deixa escrito.

Isto desafiou-nos a parafrasear o que Kerbrat-Orecchioni (1986) pensa da análise de conteúdos. A autora não hesita em validar a saída do quadro da análise linguística chamando-lhe "hipótese luminosa", não mostrando reticências em retirar outras interpretações do "isolamento imanentista" dos conteúdos. Passa assim a estabelecer nos conteúdos uma relação com a psicologia, a sociologia e a etnografia da comunicação, destacando "mecanismos do implícito" que, segundo ela, "são omnipresentes". Na realidade, Kerbrat-Orecchioni ao utilizar (e validar) a "inferência” como processo analítico, abre-nos a porta para ir ao encontro da possibilidade de que em todo o trabalho dos jovens, e concretamente no trabalho desta jovem, haveria fortes possibilidades de encontrarmos "proposições implícitas" ou ainda "pressupostos e subentendidos".

Esta "abertura" do processo analítico iria dinamizar o nosso trabalho, permitindo-nos ir descobrindo que, uma vez que a jovem fizera um trabalho muito genuíno e pessoal, todo o seu trabalho deveria ser considerado como um puzzle do qual faria parte a própria jovem na inteireza da sua identidade, os seus sonhos, as suas fantasias e o seu mundo emocional. Para além disso, a jovem destacava-se do grupo por ser uma participante muito entusiástica e motivadora das atividades. Da mesma forma, foi a partir deste novo caminho de análise que fomos ganhando progressiva consciência de que a maioria dos enunciados dos jovens participantes na pesquisa, traduzidos para a escrita, nos parecerem pouco (pobremente) demonstrativos do que disseram em contexto de trabalho porque lhes faltava uma abordagem mais profunda que trouxesse à nossa consideração o ambiente caloroso, interativo, dinâmico, afetivo e, muitas vezes, bem humorado das suas participações.

Neste trabalho fomos, por isso, pela "hipótese luminosa" aberta por Kerbrat-Orecchioni (1986) tentando descobrir nos enunciados da jovem "o implícito" que estará registrado não só no que objetivamente deixou escrito, mas também no suporte 
linguístico de índole afetiva que utiliza, e tivemos em consideração toda a envolvente em que foi enunciado e comentado pelo grupo de trabalho. Assim, nada invalida que consideremos o seu testemunho em toda a sua "imanente complexidade" "infinitamente produtiva» (KERBRAT-ORECCHIONI, 1986).

O trabalho da jovem encontra-se relacionado com experiências vividas com os espaços escolares em duas fases da sua vida. Dele fazem parte: duas imagens e um conjunto de cinco comentários a elas alusivos. A primeira é a imagem do desenho feito pela jovem da sua escola primária, quando frequentava o seu segundo ano de escolaridade, legendado por ela como "A minha escola" e dedicada ao pai que a mantém cuidadosamente guardada (Figura 1).

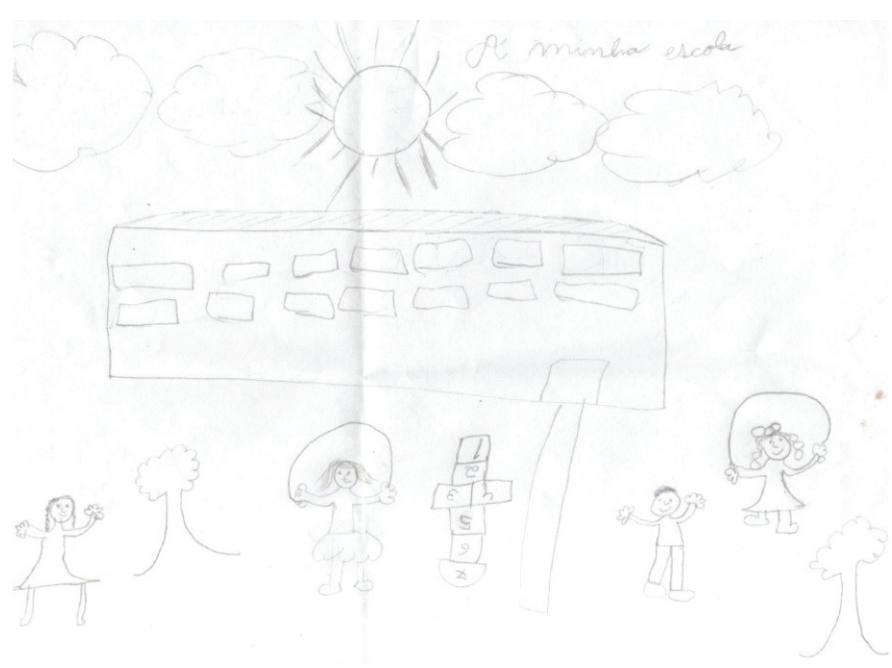

Fig. 1 - Desenho sobre "a minha escola” primária [3(E.S.), Aluna 15 anos]. Fonte: própria.

Sobre ela a jovem diz:

"A minha escolinha tinha um recreio muito grande onde nos divertíamos. Às vezes as empregadas jogavam à macaca è̀ cordinha connosco. Nós éramos felizes!"

"A minha escola primária foi aquela em que me senti melhor. Tenho imensas recordações boas de lá. Sentia-me bem com os meus colegas, com os funcionários e os professores e sentia que todos eles gostavam de mim. Nela sentia segurança e confiança. Não tinha medos nem preocupações" [3(E.S.), Aluna15 anos].

A segunda é uma Selfie feita pela mesma jovem em que enquadra o seu rosto com a maqueta da escola desejada e em que colaborou igualmente de forma entusiástica (Figura 2). 


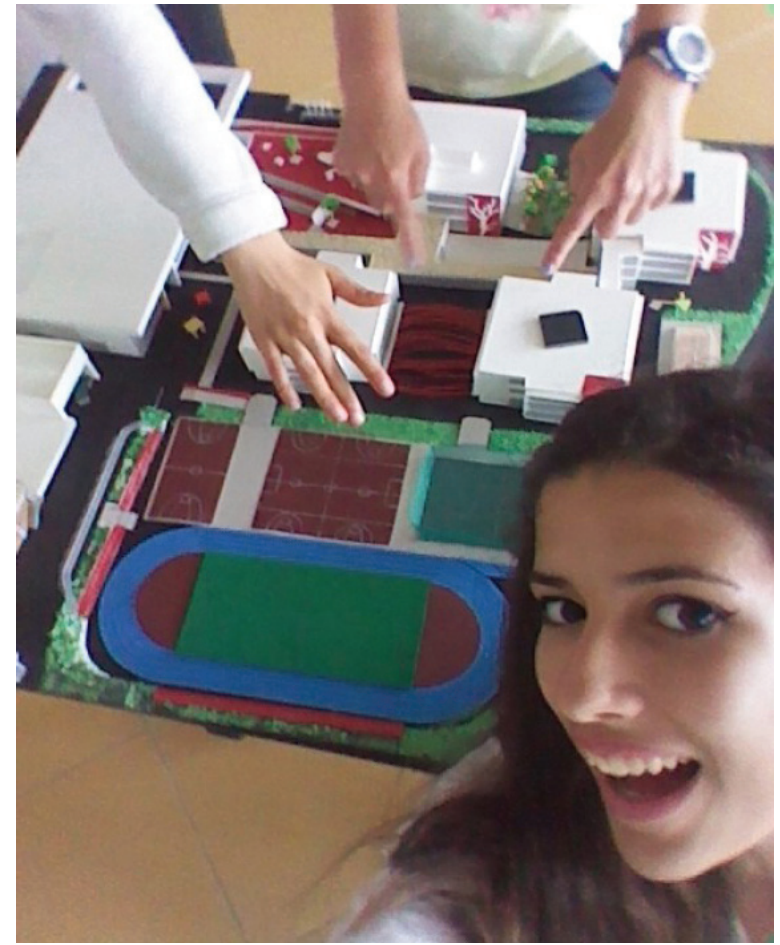

Sobre ela a jovem diz:
Fig. 2 - SELFIE de uma jovem do grupo de trabalho, "a escola dos nossos desejos" [3(E.S.), Aluna15 anos]. Fonte: própria.

"Quis prestar uma homenagem às mãos. A mão que fez a selfie e que não se vê, mas gravou este momento, e as outras que estão estendidas sobre o nosso trabalho e que ajudaram a construir uma maqueta à medida dos nossos desejos como a professora tanto nos pediu."

"Para mim a maqueta representa uma escola em que apliquei elementos que lembrassem uma casa para viver. Quando a olhava imaginava-a como se fosse a casa que um dia, se eu puder, vou construir para mim própria."

"A maqueta é branca, com relvados e árvores e nela esforcei-me para aplicar materiais que nos convidassem a tocá-los para saber de que eram feitos. Tínhamos que lhes tocar para sabermos de que eram feitos." [3(E.S.), Aluna15 anos].

A apreciação da jovem sobre o desenho revela que este se tornou, por circunstâncias complexas e que tentaremos esclarecer mais à frente, numa recordação com significado especial passando a fazer parte da sua cultura, dos seus sonhos e uma recordação estimada pelo pai. Para além disso, deixa transparecer que viveu envolta numa especial cultura institucional de tipo familiar, em que os atores se tratavam bem, eram suporte 
uns dos outros e onde não havia medos nem preocupações. Este ambiente familiar ficou impregnado nas recordações da jovem que, involuntariamente, faz novas alusões à família quando se pronuncia sobre a maqueta, (uma casa como a que um dia construirei para mim) não deixando de explicar que até os materiais aplicados "nos convidam ao tocá-los"... familiarmente.

Por outro lado, a fotografia representa o testemunho fugaz de uma atividade escolar captada no instante de um clique. Por experiência pessoal ou por mero acaso, a selfie da jovem representa um testemunho bem conseguido mesmo do ponto de vista artístico, sobretudo por razões do seu enquadramento. $\mathrm{O}$ rosto sorridente da jovem em primeiro plano torna-se apelativo convidando-nos para este evidente desafio, convite ou sugestão: que prestemos atenção à fotografia para a lermos também nos seus pormenores tentando saber o que afinal ela representa na sua totalidade.

No seu conjunto o testemunho da jovem presta-se a ser analisado em diversas perspetivas em que não se pode deixar de dar relevo ao entorno emocional que a jovem transmite quer no desenho, quer na fotografia e nos respetivos comentários. Assim, a forma peculiar como a jovem faz as suas leituras dos espaços escolares e como sentimentalmente as expressa, levam-nos a procurar entender o seu testemunho numa perspetiva "imanentemente" emocional. Por outro lado, a intensidade emocional do testemunho não reside apenas no que escreve, mas na forma como o faz com insistentes alusões ao ambiente familiar. O suporte linguístico, as palavras que escolhe, os diminutivos utilizados e "o clima" de intimidade, emprestam ao seu testemunho uma dimensão sentimental que acaba por envolver o pai, os empregados da escola, os seus colegas e...o leitor. Os espaços escolares, retratados com esta intensidade podem explicar como estas leituras não são atos puramente descritivos, mas uma atividade narrativa em que se encontram e cruzam teias de ordem sensitiva, emocional, sentimental e autobiográfica e que parecem todos expressar a história pessoal da jovem e as vias que está a escolher para construir a sua identidade.

A memória dos espaços escolares aqui registrada não morreu " $n$ 'A minha escola". Está ainda a fazer um longo percurso. Iniciada na escola primária onde foi guardada, assimilada e vinculada, nunca se perdeu da memória da jovem e do pai e acaba por se redescobrir agora com todos os colegas de trabalho e, graças a um qualquer imprevisto, revive neste texto, que a reconhece como ponto marcante de uma biografia pessoal e de uma identidade.

\section{Identidades e Emoções - Elos para uma ligação}

Abordaremos de seguida a questão da construção da identidade como uma fase típica da adolescência e, como tal, impregnada pela vida da escola. Começaremos então por pôr em destaque que a escola é um espaço comunicacional, divulgando e reprodu- 
zindo culturas presentes na sociedade. Internamente, ela é tipicamente um meio codificador, transmitindo valores, ideias, conhecimentos e símbolos que, durante a escolaridade acabam por se transmitir osmoticamente às identidades. Mas, será só isso? Façamos entretanto uma pequena abordagem à questão da identidade.

Para Castells (1999) as identidades ligam-se às histórias de vida (narrativas), ao futuro, aos sonhos e fantasias de cada adolescente. Elas permitem a perceção de serem sujeitos únicos tomando consciência de si mesmos. É uma autoconstrução. Por seu lado Louro (1999) leva-nos a ter em conta que, na adolescência os jovens são sujeitos a identidades transitórias e contingentes, provisórias, descartáveis, rejeitadas e abandonadas, nada impedindo que diferentes quadros identitários se imbricam uns nos outros a fim de contribuir para "o sentimento de identidade" (DESCHAMPS \& MOLINER, 2009, p.147). Hall (2005), por sua vez, reforça este caráter contraditório da identidade descrevendo-a com forças internas que nos empurram em diversas direções com um caráter instável, fragmentado e plural. Serão essas forças, os conflitos de valores, a necessidade de reconhecimento, o julgamento da imagem de si e dos outros, que irão balizar as identidades. Também Eagleton (2005) reforça esta conflitualidade afirmando que num mundo inteiramente constituído por diferenças, teremos todos que construir as nossas identidades (afirmar e sedimentar as nossas diferenças) se quisermos sobreviver. Rorty (2007) afirma que só somos uma identidade quando as nossas contingências particulares fazem de cada um de nós um eu, e Giddens (2002), por fim, chama a atenção para a auto-identidade que o indivíduo instaura por um processo reflexivo, encontrando-se nas diversas situações sociais vividas e dentro do quadro geral psicológico do indivíduo, incluído o corpo.

Do que fica dito, se por um lado a identidade é um processo de interação entre os indivíduos, tendo como fatores cruciais o desejo de pertença que nos impele para os outros e de não pertença que nos atrai para nós próprios, é também fruto de um conjunto de crenças e representações sobre nós mesmos. Por outro lado, a identidade extravasa a experiência social, sendo um investimento ditado pelo dinamismo da própria pessoa, um jogo de construções sociais e pessoais em que alguns relevam o papel do próprio corpo, o sentimento de $e u$, de termos um corpo em que estamos condenados a viver.

Na realidade andamos em torno de um conceito na esperança de encontrar a chave, o último elo que nos faltava: a dimensão corporal da identidade. Somos uma identidade porque nos reconhecemos num corpo que nos dá o sentimento de sermos nós próprios e que nos diferencia. São inúmeros os estudos que na atualidade gravitam em torno da identidade como realidade corporal. Como exemplo referimos a exposição no MoMA (Museu de Arte Moderna de Nova York) sobre o corpo e a "terrível verdade do tempo" (LUCAS, 2014), em que Nicholas Nixon nos dá em imagens de quatro irmãs fotografadas sempre pela mesma ordem, durante 40 anos, - "Forty Years of The Brown Sisters" - e que representam o testemunho emocional da viagem do corpo e das suas trágicas transformações ao longo desse tempo. Nas imagens o leitor recria-se e interroga-se sobre as histórias de cada uma das irmãs procurando destacar as diferenças e as per- 


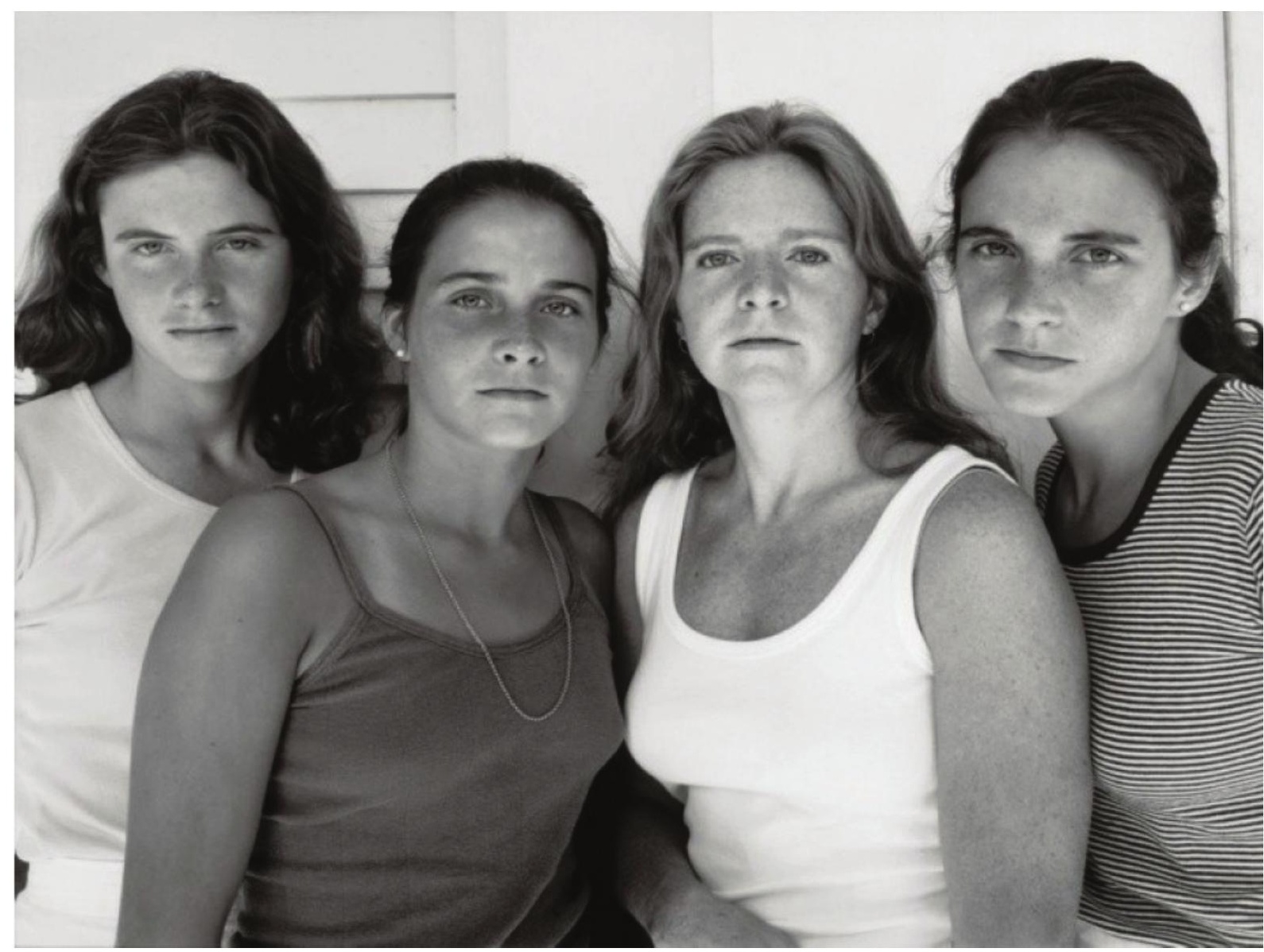

Fig. 4 - Fotografia de 1978 das quatro irmãs (na mesma ordem da fotografia da Figura 3) do autor Nicholas Nixon, obra em exposição no MoMA. Fonte: http://www.publico.pt/culturaipsilon/noticia/quatro-mulheres-em-40-imagens-ao-longo-de-40-anos-1680506

estas considerações) não podemos deixar de realçar como o autor privilegia os nossos processos mentais e relacionais, lembrando, também ele, que o lastro do nosso $\boldsymbol{e u}$ autobiográfico se constrói a partir das nossas memórias, das nossas emoções, que se tornam progressivamente nas nossas histórias e nas nossas identidades. 


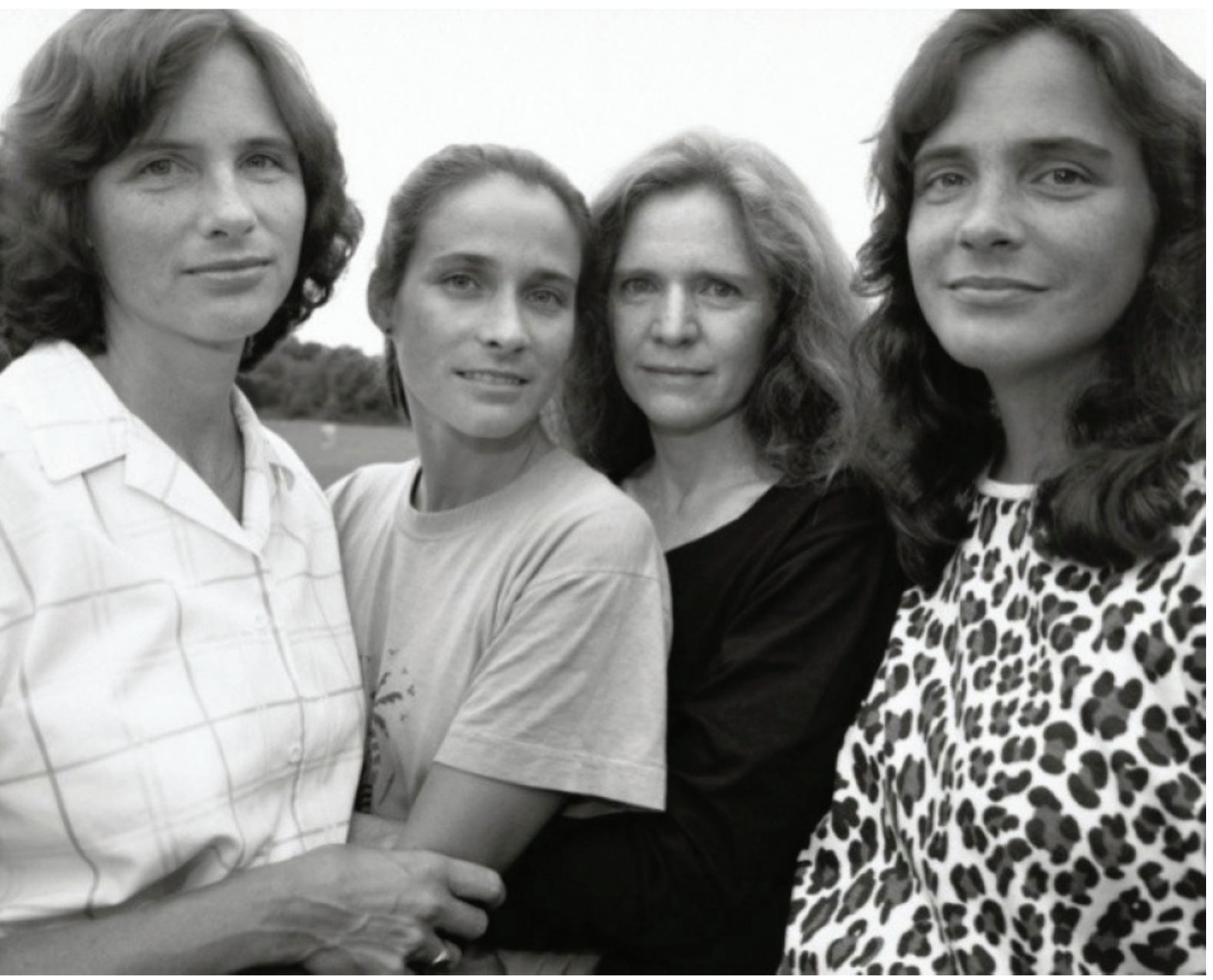

Fig. 5 - Fotografia de 1988 das quatro irmãs (na mesma ordem da fotografia da Figura 3) do autor Nicholas Nixon, obra em exposição no MoMA. Fonte: http://www.publico.pt/culturaipsilon/noticia/quatro-mulheres-em-40-imagens-ao-longo-de-40-anos-1680506

\section{Conclusões}

Como conclusões podemos afirmar que a análise e assimilação dos espaços escolares por via sensitiva marca de forma impregnante a vida dos jovens. Muito possivelmente inscrevem-se de forma muito permanente e vinculada porque as assimilamos e revivemos por via sentimental e emocional e que cada um vai escrevendo no longo livro da sua identidade. 


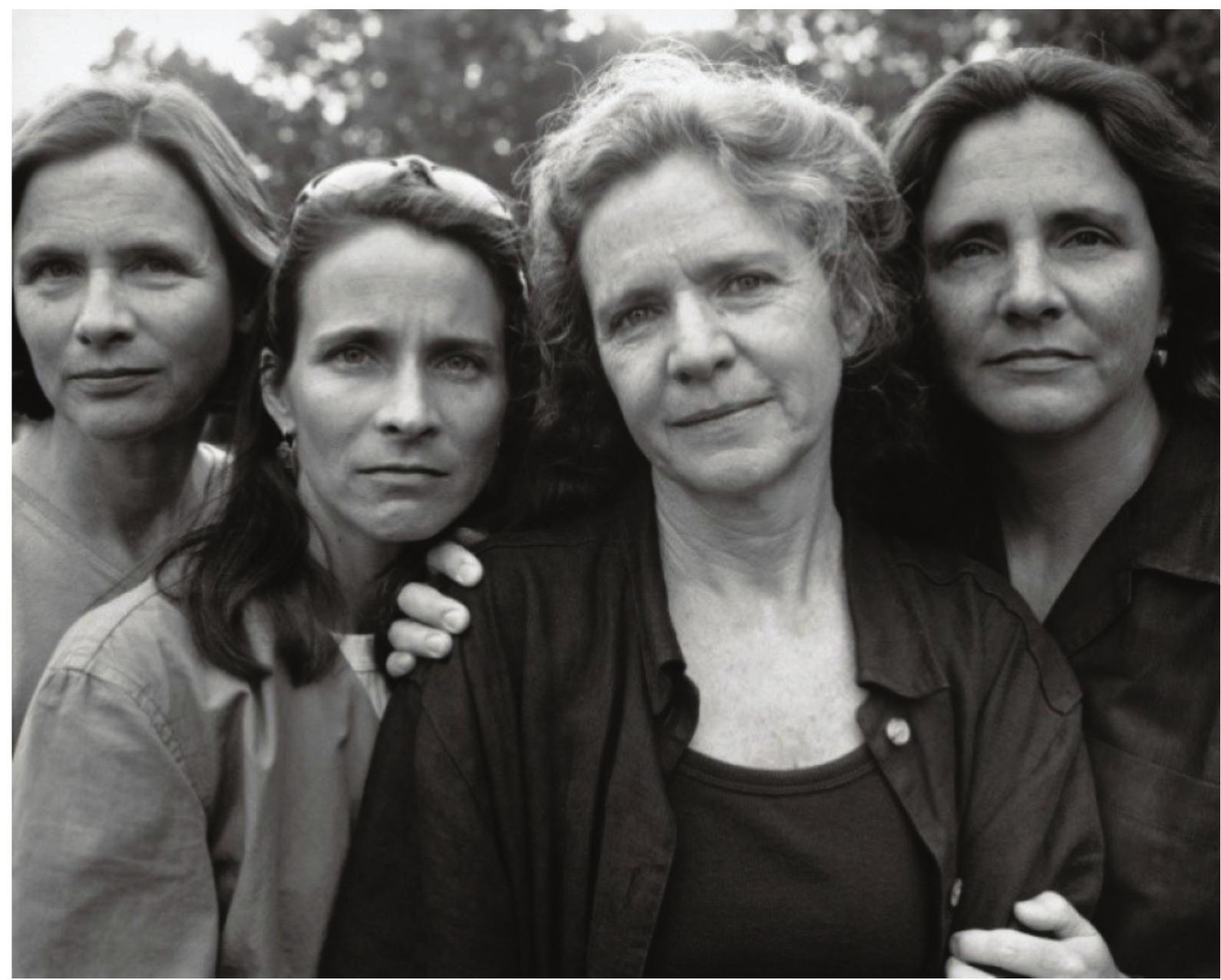

Fig. 6 - Fotografia de 1999 das quatro irmãs (na mesma ordem da fotografia da Figura 3) do autor Nicholas Nixon, obra em exposição no MoMA. Fonte: http://www.publico.pt/culturaipsilon/noticia/quatro-mulheres-em-40-imagens-ao-longo-de-40-anos-1680506

Por outro lado, a forma como foram interiorizados e explicitados os testemunhos aqui referidos, leva-nos também a considerar que estaremos, por via da análise sensitiva e emocional, a descobrir inauditos aspetos de um novo conhecimento e apropriação cultural dos espaços com consequências ainda pouco conhecidas no processo educativo e no processo de desenvolvimentos dos nossos jovens. 


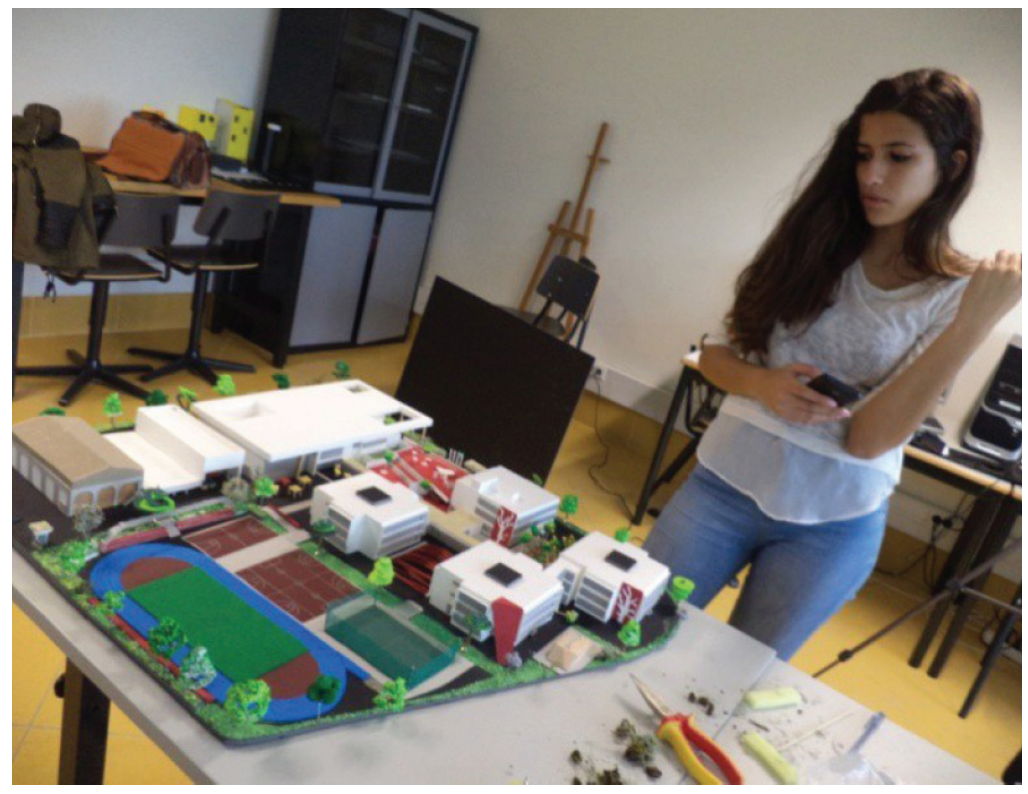

Fig. 7 - Fotografia tirada pela investigadora à jovem do grupo de trabalho e autora da selfie, num contexto que reflete a colocação do eu da aluna face "à escola desejada em maqueta", resultante da experiência vivida numa atividade escolar, e nas relações que estabeleceu com os seus espaços escolares. Fonte: própria.

\section{Referências bibliográficas}

CASTELLS, Manuel (1999). Vol. II: O poder da Identidade. $2^{\text {a }}$ ed. S. Paulo: Paz e Terra. ISBN 8521903367

COULON, Alain (1995). Etnometodologia e Educação. Petrópolis: RJ, Vozes.

DAMÁSIO, António (2010). O livro da consciência: a construção do Cérebro Consciente. Temas e debates. Lisboa: Círculo de leitores. ISBN 9789896441203

DESCHAMPS, Jean Claude \& MOLINER, Pascal (2009). A identidade em psicologia social: dos processos identitários às representações sociais. Tradução de Lúcia M. Endlich Orth. Petrópolis: Vozes. ISSN 1518-3483

EAGLETON, Terry (2005). Depois da teoria: um olhar sobre os estudos culturais e o pós-modernismo. Rio de Janeiro: Civilização Brasileira. 2005.

GIDDENS, Anthony (2002). Modernidade e identidade. Rio de Janeiro: Jorge Zahar.

HALL, Stuart (2005). A identidade Cultural na pós-modernidade.10a edição. Rio de Janeiro: DP\&A. 
KERBRAT-ORECCHIONI, Catherine (1980). Lénonciation de la subjectivité dans le langage. Paris: Armand Colin. Volume 3, Número 1, p. 162 - 167 [consultado a 29-042015] Disponível em URL: http://www.persee.fr/web/revues/home/prescript/article/ mots_0243-6450_1981_num_3_1_1044_t1_0162_0000_2

KERBRAT-ORECCHIONI, Catherine (1986). L'implicite. Paris: A. Colin. Volume 39, Numéro, p. 44 - 45. [consultado a 29-04-2015] Disponível em URL : http://www.persee.fr/web/revues/home/prescript/article/igram_0222-9838_1988_num_39_1_2033_ t1_0044_0000_5

LOURO, Guacira Lopes (1999). Género, Sexualidade e educação. Uma perspetiva pós estruturalista. Petrópolis: Vozes.

LUCAS, Isabel (Dez. 2014). "Quatro mulheres em 40 imagens ao longo de 40 anos", de Nicholas Nixon. Revista 2 do Público - online, de 28 de dezembro de 2014 [consultado a 01-05-2015] Disponível em URL: http://www.publico.pt/culturaipsilon/noticia/ quatro-mulheres-em-40-imagens-ao-longo-de-40-anos-1680506

RORTY, Richard (2007). Contingência, ironia e solidariedade. São Paulo: Martins Fontes. 